\title{
SEG Algorithm
}

National Cancer Institute

\section{Source}

National Cancer Institute. SEG Algorithm. NCI Thesaurus. Code C49037.

A computer algorithm that provides a general method for partitioning the globular and non-globular regions of a protein sequence. 